\title{
A New Online and Offline Blended Teaching System of College English Based on Computer Internet Technology
}

\author{
Ping Li, ${ }^{1}$ Hua Zhang $\mathbb{D}^{1},{ }^{1}$ and Sang-Bing Tsai $\mathbb{D}^{2}$ \\ ${ }^{1}$ Foreign Language School, Weifang University, Weifang, Shandong 262100, China \\ ${ }^{2}$ Regional Green Economy Development Research Center, School of Business, Wuyi University, Nanping, China
}

Correspondence should be addressed to Hua Zhang; zhanghua198316@126.com and Sang-Bing Tsai; sangbing@hotmail.com

Received 25 August 2021; Revised 17 September 2021; Accepted 4 October 2021; Published 14 December 2021

Academic Editor: Guoqiang Wang

Copyright ( 2021 Ping Li et al. This is an open access article distributed under the Creative Commons Attribution License, which permits unrestricted use, distribution, and reproduction in any medium, provided the original work is properly cited.

\begin{abstract}
Through the analysis and research of the multimedia teaching platform system based on computer Internet technology, this paper proposes constructing a network multimedia teaching platform system based on streaming transmission to realize the sharing of excellent teaching resources in colleges and universities and the development of education and teaching. The design and development of each module of the teaching platform are completed, and the realization technology of each module function is explained. We completed the design and implementation of some auxiliary functions of the teaching platform, including the system usage help module, resource search module, and online on-demand playback functions. After the experiment, we compare the changes of students' English anxiety before and after the experiment and conduct interviews with them. The results show that the application of the Internet-based scaffolding teaching model in college English reading teaching can alleviate students' English learning anxiety. Through interviews to understand students' feedback and evaluation of the new teaching model, it was found that most students hold positive evaluations of the Internet-based scaffolding teaching model, believing that the new teaching model can stimulate students' English learning enthusiasm and increase confidence in English learning.
\end{abstract}

\section{Introduction}

The Internet has also had a greater impact on college English teaching, and many teachers have adopted multimedia and other tools in their teaching. Internet teaching also brings about powerful challenges to teachers. Teachers need to have more knowledge than before. They are no longer a single source of knowledge under the traditional teaching model. Students can acquire more knowledge through the Internet, and they must also learn how to find information and how to find resources from the Internet by themselves $[1,2]$.

As a language course, college English is an important course at the junior high school stage. It is highly applicable and requires long-term systematic study and training. Under the traditional teaching model, teachers always feel exhausted, and students' learning enthusiasm is not optimistic. The research on the blended learning model of college English reading classrooms can cultivate the information literacy of primary school students $[3,4]$. Introducing learning resources from the Internet into classroom teaching will help cultivate information awareness and literacy. Modern education has used various communication technologies and computer technologies to construct a remote teaching mode that separates teachers and students. Traditional classroom teaching has been transforming to multimedia classroom teaching and virtual classroom teaching constructed through the Internet, and more and more schools are beginning to pay attention to the construction of quality courses. Integrating the teaching resources of excellent teachers for more learners and teachers to learn from has become a problem before us, using the streaming technology of streaming media [5]. The multimedia video resources are compressed, encoded, streamed, and packaged into continuous data packets for transmission to the client. Realizing the real-time transmission and playback of excellent teaching resources provides us with a good solution [6]. 
The three-tier structure includes the client, WEB server, and database. After receiving the user's request, the WEB server searches the database for the resource requested by the user and then transmits it to the target through network streaming. The platform provides learners with quick query functions. Learners can not only use keywords to inquire but also inquire according to the chapters and disciplines of the knowledge they have learned. The background database of the teaching platform system stores a large amount of teaching resource information and user information. The system sets up a unified administrator to manage the teaching resource information and users uniformly to ensure the safety and reliability of courseware resources and user information. After the user logs in to the platform, he queries and selects the resource information he needs and realizes the on-demand viewing function through the streaming media server and streaming video player. The Internet-based scaffolding teaching model integrates the Internet teaching concept to better realize the classroom teaching effect.

\section{Related Work}

The United States proposes building a "national information infrastructure" [7]. With the help of personal computers and the Internet, the education industry has realized the digitization of education environment, education content, and education management. For example, the United States initiated the "Digital Library Initiative Project" and "National Digital Library Project" to popularize digital libraries in cities and schools; the digital publishing industry has sprung up, with the help of Internet distribution channels, and the media, using online payment as the main means, changed the pattern of the traditional publishing industry [8].

The integration of computer networks and language teaching does not rely on simple research in one or two disciplines to solve problems. Its emergence is based on the research of multiple theories, and it is the continuous optimization and integration of current discipline research [9]. The rapid development of computer network technology and alternate learning theories are integrated with each other, which regulates the development characteristics of language teaching in this environment. Behaviorist computer-aided language teaching, interactive computer-aided language teaching, and integrated computer-aided language teaching have appeared [10]. While fully affirming the guiding significance of learning theory to teaching practice, researchers have carried out more in-depth research [11]. Relevance learning theory is the best choice for the construction of language teaching models in the current computer network environment [12]. It believes that teaching is the connection between information exchange and the process of circulation, and information technology is the only prerequisite medium. This theory is more suitable for cultivating students to realize individualized and creative independent learning. Researchers generally suggest that the various learning theories such as behaviorism, cognitivism, constructivism, and relevance should be scientifically connected and integrated [13].
The first category is foreign commercial platforms, which generally cost more to develop and use, but they can provide users with good services and have better platform performance. These platforms have strong technical force and are mature and stable but generally have higher service costs, such as the Blackboard teaching platform. The second category is domestic commercial platforms, such as the THOEL online teaching platform of Tsinghua University and the sky classroom developed by Nanjing Yixue Education Software Co., Ltd. The domestic online teaching platform is more suitable for China's teaching needs and is more in line with the reality of China's higher education. The third category is a network teaching platform independently developed by universities according to the needs of their teachers, students, and teaching and is only open and used within the scope of the university. This type of teaching platform is developed according to the characteristics and needs of the university itself, and the manpower and material resources consumed by the development are not high but may be inferior to the first two types of platforms in terms of compatibility and adaptability. The fourth category is open-source software. Since these software programs have open source codes, users can partially modify the source code of this type of software to meet their own teaching or learning needs $[14,15]$. There are many such platforms, such as the Moodle platform.

Related scholars put forward the concept of blended learning to provide students with personalized help, find and formulate learning resources and methods in line with their personality and learning style, and organically integrate these personalized resources to provide targeted development for students [16]. Researchers emphasize that blended learning is an optimized learning model that integrates modern educational technologies that can assist in achieving expected learning goals, while taking projects as the core [17]. Relevant scholars have proposed that blended learning is an innovative education form centered on learners, which integrates various learning theories, diversified teaching methods, teaching concepts, and advanced educational technology [18-20].

Academic self-efficacy directly affects the degree of participation in online open courses and indirectly affects the persistence of online open courses. The existence of teachers can enhance learners' participation and directly affect learners' learning persistence and improve their desire to complete the course. The perceived usefulness of learners when using the online open course platform greatly affects their learning participation, but it does not directly affect the persistence of online open course learning. The ease of use of the online open course platform does not significantly affect learner participation, but it directly affects the persistence of online open course learning. Participation in online open courses directly affects the persistence of online open courses. Therefore, when designing online open courses, teachers should formulate specific plans to meet the needs of learners and encourage them to actively participate in online open courses, so as to improve course completion [21-23]. 


\section{College Students' English Mixed Teaching Mode Supported by Computer Internet Technology}

3.1. Key Technologies to Support Computer Internet Mobile Learning. The technologies that support computer Internet mobile learning include mobile terminal equipment and wireless network access methods. Computer Internet mobile learning terminal equipment is one of the three major elements of the computer Internet mobile learning system environment. It is a basic part of the development of computer Internet mobile learning and a necessary condition for the implementation of computer Internet mobile learning activities. The online and offline hybrid teaching mode of college English using computer Internet technology is shown in Figure 1.

\subsection{Analysis of Blended Teaching}

3.2.1. A Mixture of Interpersonal and Human-Computer Interaction in and out of Class. The interpersonal interaction of traditional classroom teaching takes place in class. This kind of interaction is a one-way interaction. It supports the interaction between teachers and students in class through modern multimedia technology devices such as mobile smartphones, computers, and projectors through the implementation of classroom barrage, classroom real-time rush answers, lottery questions, and random group discussions in the classroom. After class, through resource sharing, group collaboration, teacher-student Q\&A, student-student discussion, and so forth, this multidirectional interaction is the interaction between teachers, students, and teaching media. It is also in class, offline, and online.

\subsubsection{Mixed Teaching Media Supported by Computer In-} ternet Technology. The mixed teaching supported by computer Internet technology can choose from various teaching media with rich functions. In the organization of teaching, in addition to traditional teaching media "books, blackboards, projectors," and so forth, modern mobile communication technology terminal equipment, such as "mobile phones, tablets, and notebooks," can be used as interactive tools in the classroom and can also be used outside the classroom.

\subsubsection{Mixed Teaching Environment Supported by Computer Internet Technology. Blended teaching is not a fixed, simple mixture of "offline teaching from person to person" and "online self-directed learning." The hybrid teaching envi- ronment enriches traditional classroom teaching methods, uses mobile devices to communicate and interact online, and mobilizes students' interest in learning and classroom at- mosphere. Mobile devices have the characteristics of wireless transmission. Teachers and students can use video and voice calls, electronic whiteboards, and other functions outside the classroom to perform wireless projection and multiscreen interaction, so as to realize online teaching.}

3.2.4. Mixing of Teaching Content and Resources. College English requires a hybrid teaching model supported by computer and Internet technology. In addition to the traditional textbook knowledge, its teaching content also includes electronic courseware, video, audio, electronic documents, and other learning materials uploaded by the teacher. The content of the learning materials can be passed by the teacher. Students can use mobile devices to obtain teaching resources in class or at any other time, supplemented by classroom learning, or perform informal contextual learning. In informal situations, students can search for corresponding learning resources through WEB, foreign language learning APP, WeChat official account, and so forth according to their individual learning needs.

\subsection{5. "Dominant-Subject" Teaching Structure Is Mixed.} The constructivist teaching concept believes that teaching should take learners' original knowledge and experience as the growth point of new knowledge and guide learners to actively construct new knowledge and experience from their original knowledge and experience. Teachers and students as well as students and students should communicate and question one another in the process of exploring certain issues together. In this exploration and interaction, it is necessary to give full play to the guiding role of teachers and fully reflect the main position of students. Whether it is offline collective face-to-face instruction or online individual instruction, teachers are the planners, organizers, and guides of the entire teaching process. The appropriate teaching strategy should be selected according to the student's learning situation. Through meaning construction and repeated training, students are guided from understanding to mastering the structure of words, grammar, and sentence structure, until they are used proficiently, and the language knowledge is transformed into language skills.

\subsection{Data Mining of College Students'English Blended Teaching}

3.3.1. ID3 Algorithm. $S_{i}$ is the number of samples in class $C_{i}$. The class label has $m$ different values, and $m$ different classes $C_{i}(i=1,2, \ldots, m)$ are defined.

$$
I\left(S_{0}, S_{1}, S_{2}, \ldots, S_{m-1}\right)=\prod_{i=0}^{m-1} \log _{2}\left|P_{i}\right| .
$$

In the above formula, $P_{i}$ is the probability of any sample belonging to $C_{i}$. Since the information is expressed as a binary code, it is based on the logarithmic function 2 .

Suppose that attribute A has $v$ different values $\{$ a1. a2 ... av\}. The information entropy divided into subsets by $\mathrm{A}$ is given by

$$
\begin{aligned}
E(A) & =\operatorname{Info}\left(\frac{D_{j}}{(D)}\right) \cdot \prod_{j=0}^{v-1}\left|D_{j}\right|, \\
D_{j} & =1-S_{1 j}-S_{2 j}-\cdots-S_{m j}, \\
I\left(S_{0 j}-S_{1 j}-S_{2 j}, \ldots, S_{(m-1) j}\right) & =P_{i j} \cdot \prod_{i=0}^{m-1} \log _{2}\left|P_{i j}\right| .
\end{aligned}
$$




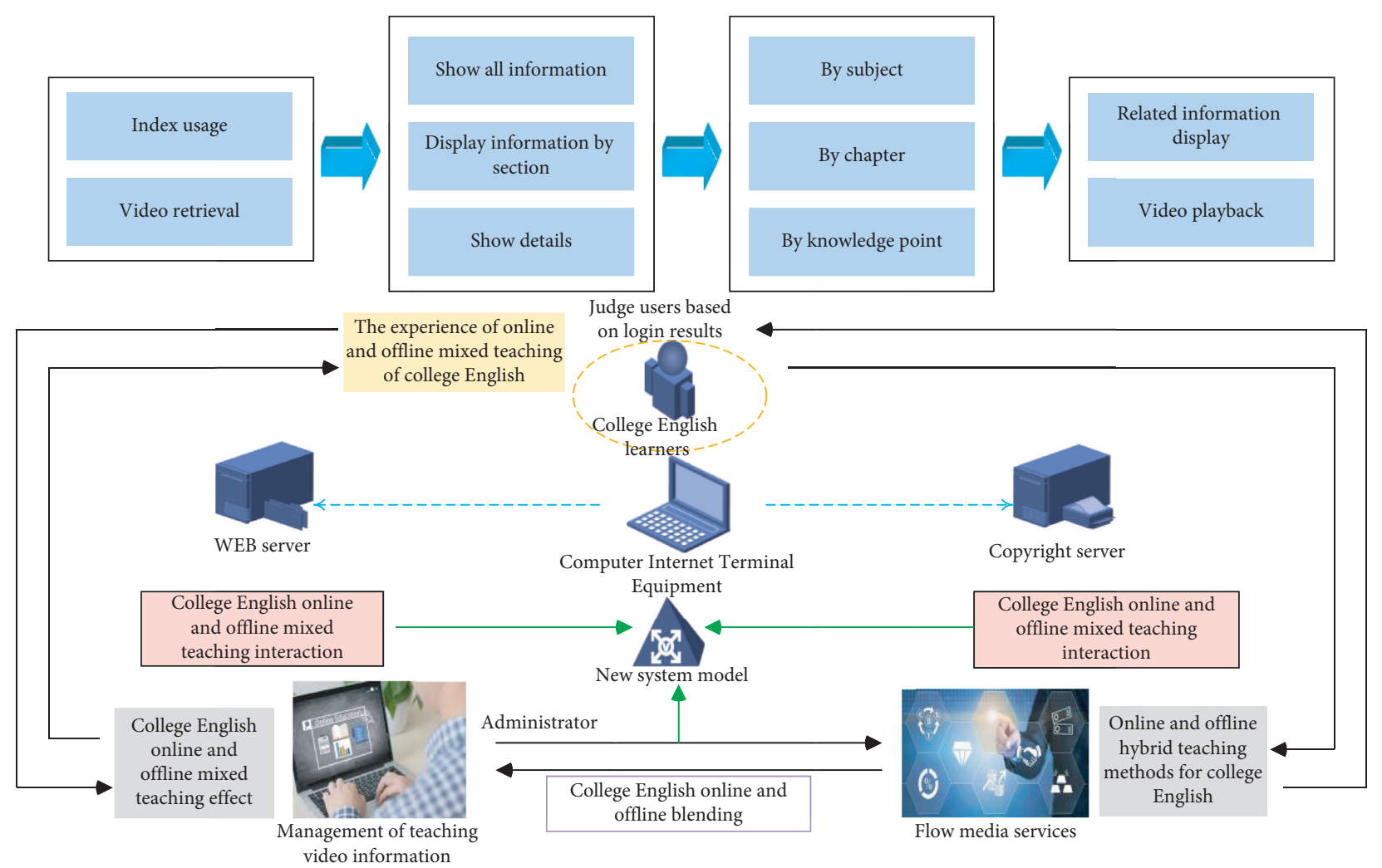

Figure 1: Online and offline mixed teaching mode of college English using computer Internet technology.

In the above formula, $P_{i j}$ is the probability that the sample in $S_{j}$ belongs to class $C_{i}$. The information gain obtained by branching on attribute $\mathrm{A}$ can be obtained by the following formula:

$$
Z(A)=E(A)+I\left(S_{0}-S_{1}-S_{2}-\cdots-S_{m-1}\right) .
$$

3.3.2. C4.5 Algorithm. When the ID3 algorithm splits, it pays more attention to splitting multivalued attributes. Such a division looks very fine, but it is actually meaningless. But ID3's improved algorithm C4.5 makes up for this shortcoming, because the $\mathrm{C} 4.5$ algorithm introduces the concept of gain rate to split the attributes.

The C4.5 algorithm uses a formula to calculate the split information; the formula is

$$
\gamma(D)=\frac{1}{D} \cdot \log _{2} D_{j} \cdot \prod_{j=0}^{\nu-1}\left|D_{j}\right| .
$$

Then we select the attribute with the largest gain rate for division. The calculation method is similar to ID3. The formula is

$$
\chi(A)=\frac{Z(A)}{\gamma(A)}
$$

\section{System Analysis and Design of Online and Offline Mixed Teaching Platform}

4.1. The Overall Design of College English Online and Offline Mixed Teaching Platform. The video teaching information contained in the platform system is prepared in advance or collected in real time by video and audio acquisition equipment, and then the prepared streaming media format files are released through the streaming media server, and the web page information is released through the WEB server.

After the user enters, the platform system first presents the login page to the user, asking the user to enter their user name and password. The platform system will enter the background database for query and comparison. The identity is a system administrator or a learner. Users can browse the resource information of the platform system according to their needs, select the learning resources they need, and conduct online learning. If it is the first time to register, you can also view the instructions for use of the system; if the user is an administrator, you will enter the administrator interface. The administrator can view current user information and video resource information. If the user information is not found in the background database, the user will be prompted whether the user name or password has been entered incorrectly. The system workflow of this platform is shown in Figure 2. 


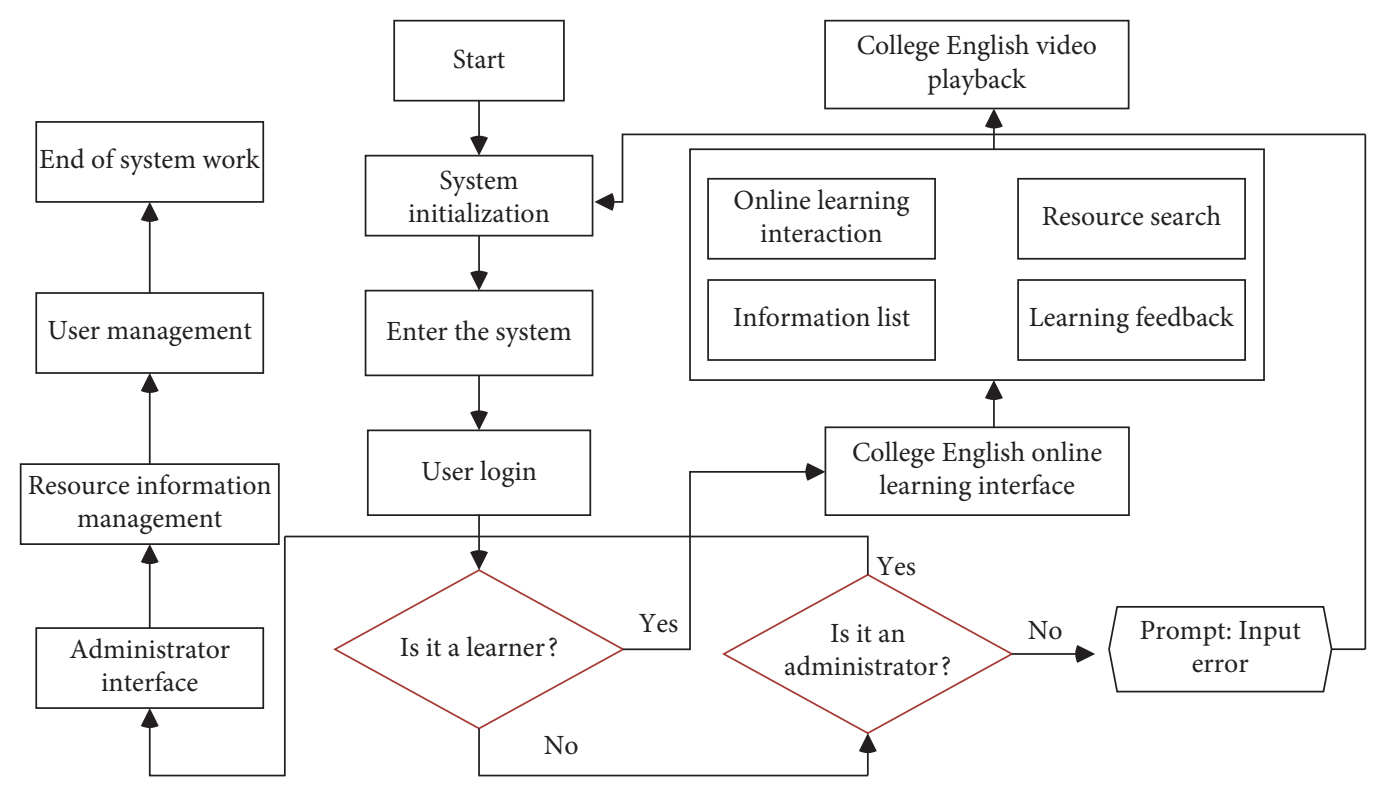

FIGURE 2: Workflow of college English online and offline mixed teaching system.

4.2. Production and Release of Streaming Media Courseware. Multimedia courseware is the use of multimedia technology to transform boring course content into vivid multimedia information for learners to learn. The use of multimedia technology can express the knowledge and concepts that learners find difficult, abstract, and difficult to understand in the form of animation, which is convenient to learners' learning and understanding. The production of multimedia courseware first needs to convert teaching materials into digital information, generate a digital video file, and then stream the file to make a stream format file and then add the logo information we need to the stream format file. In the technology, parameters such as Marker and Command can be added to the stream file. This identification information will make the client software produce some effects we need when playing the stream file. When the client software reads the label, it will generate a Marker Hit event and pass a parameter. This parameter is the content corresponding to the label.

At the same time, the content of the label will be displayed in the text box of the client. This shows that we should write the stream format file. Some labels are added to the corresponding positions, so that the entire online courseware can be coordinated. In order to enable the client to use the browser to watch the courseware, we must also use Dream Weaver software to make the corresponding web page, insert the Media Player plug-in in the web page, and use the VBscript scripting language to write the corresponding processing program to handle the Marker Hit event. You can also add some control buttons to realize the user's playback control of the video information. The logical structure of streaming media file playback and information flow delivery is shown in Figure 3.
For the production of streaming media courseware, you can choose the teacher's Windows Media Encoder tool to record the teacher's real-time lectures into ASF format files, and you can also use the Windows Media Author tool to convert the recorded audiovisual teaching resource files into ASF streaming format for release. Both methods require Media ASF Indexer to add tags and descriptions to the stream format file to achieve the synchronization display of the relevant learning materials.

4.2.1. Publishing Streaming Media Courseware Based on WEB. Publishing streaming media courseware based on WEB is to put the prepared streaming media courseware on the WEB server, and users can download and watch it through the browser or watch it online. The efficiency of publishing courseware in this way is relatively low, and there is no real-time guarantee, and it cannot support too many users to use it at the same time.

4.2.2. Release Based on Streaming Media Server. This method of publishing streaming media courseware should be realized by using a streaming media server. Windows Media Server is a component provided by the Windows 2010 server operating system, which can stream multimedia content from low-bandwidth to high-bandwidth networks. The streaming media server component is composed of Windows Media Component Service and Windows Media Manager. Windows Media Component service is a series of services running on Microsoft Windows 2010 server. These services can transmit audiovisual information to users through unicast, multicast, and broadcast. Windows Media 


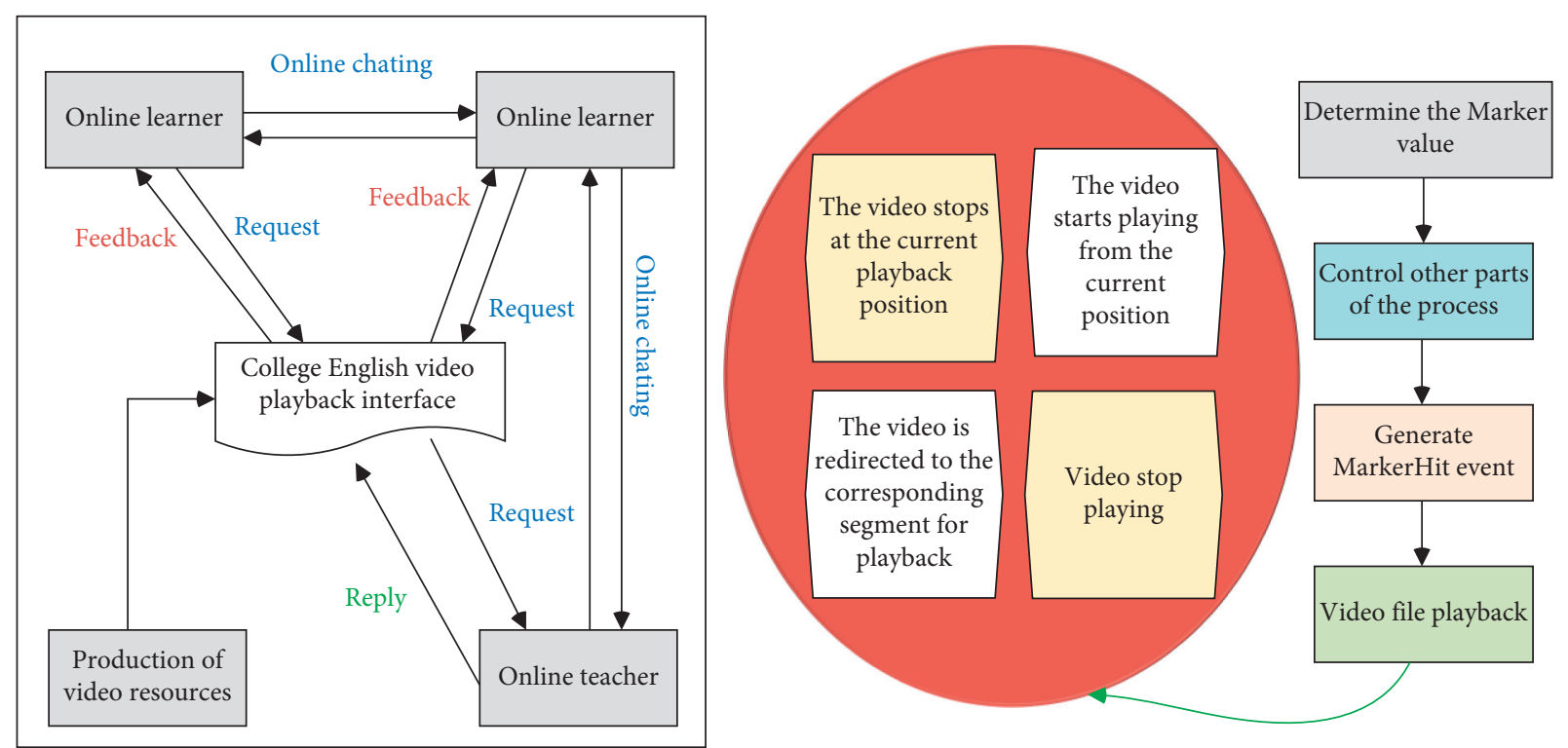

FIGURE 3: Logic diagram of streaming media playback and information flow delivery.

Manager is a series of WEB pages used to manage Windows Media Component services, which can manage and control local servers.

\subsection{The Design of Various Functional Modules of College English Online and Offline Mixed Teaching Platform}

4.3.1. Design of User Login Module. The system of this platform must be registered as a member to $\log$ in to the system for learning. The user must enter his user name and password through the login interface before entering the system of this platform for learning. After the system obtains the account and password entered by the user, it queries the USER data table for a record that matches the account password through a query statement. If rs is empty, it means that the user's information does not exist in the database; that is, the user is not a registered user of the platform system or the user name or password is entered incorrectly, and the user is prompted to log in again. If rs is not empty, it means that the user is a normal registered user; that is, the login is successful, and then the user's identity is judged according to the user's type. User type information is an important identification information for users of the system on this platform. Different identification information means different user identities and also means that they have different operating permissions. Therefore, the identification information will always exist until the user logs out of the system.

First we use the request object to obtain the user name and password entered by the user to ensure that they are not empty and then create an instance of the recordset object rs, find the record consistent with the information entered by the user from the user table USER, and assign it to rs. If it is not empty, we save the value type of the user type in the variable usertype. After obtaining the value of the usertype variable, the user's identity information can be determined, where 1 corresponds to the administrator, 2 corresponds to the ordinary learner, and the web page will jump to the corresponding page. If the value of usertype is neither 1 nor 2 , it means that the user entered the user name or password incorrectly, and the user still stays on the original page, waiting for the user to confirm the identity, and jump to the corresponding interface. In order to prevent unnecessary losses caused by malicious access to the platform system, the user's cookies value is set when the user logs in. This value will record the user's login information and save it until the user logs out of the system. Each time a user visits a page, the user will first check whether the user's cookies value exists.

4.3.2. The Design of the Administrator Module. The user management flowchart is shown in Figure 4. The video playback interface is an important module of the platform system, and its function is to realize streaming media playback. This interface can integrate real-time teaching videos of excellent teachers for users to watch on demand. At the same time, teachers' teaching plans will be displayed synchronously on key and difficult knowledge points to allow students to deepen their understanding of this part of knowledge. The combination of this interface and the server can also provide online users with real-time and non-realtime online communication.

\section{Research Results and Analysis}

5.1. Analysis of the Results of Students' College English Pretest. In order to ensure that the reading anxiety levels of the two classes before the experiment are the same, before the experiment, this paper analyzes the results of the questionnaires of the two classes from three dimensions (text comprehension anxiety, emotional anxiety, and cultural background anxiety).

It can be seen from Figure 5 that, before the experiment, from the perspective of text comprehension anxiety, the 


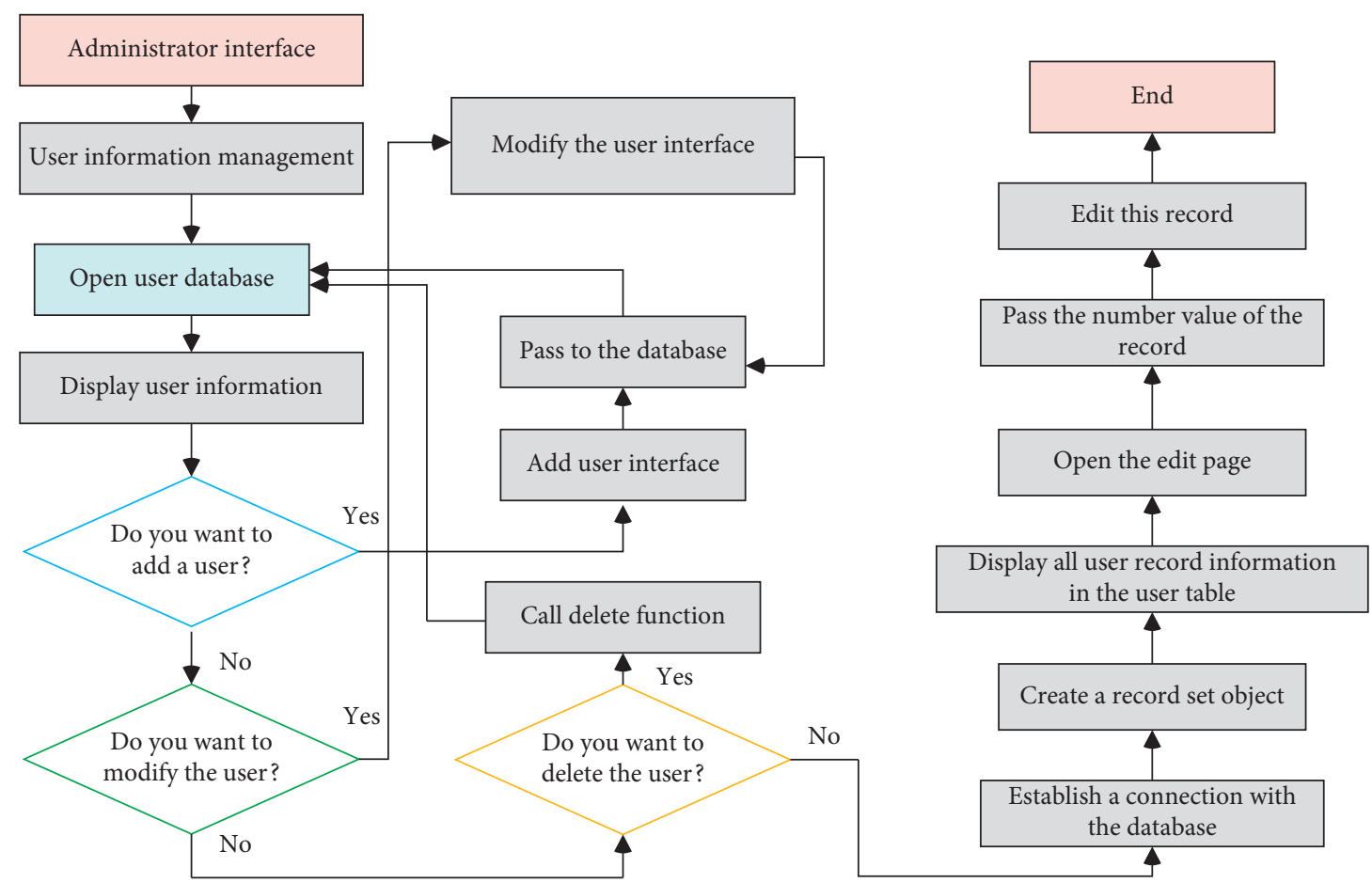

Figure 4: Flowchart of user management for online and offline mixed teaching of college English.

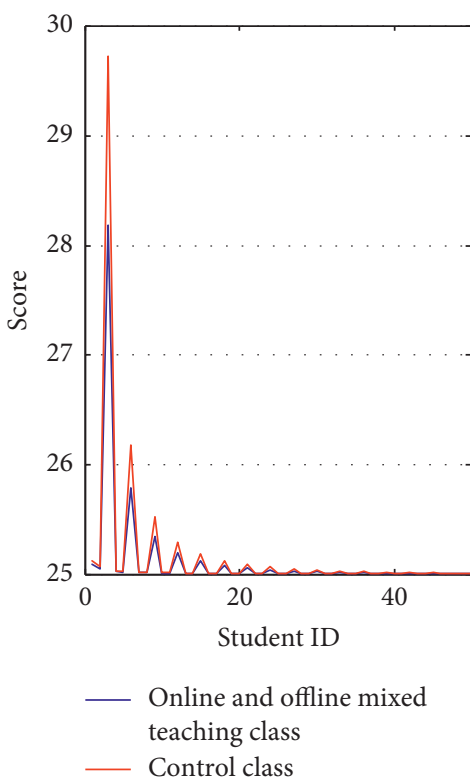

(a)

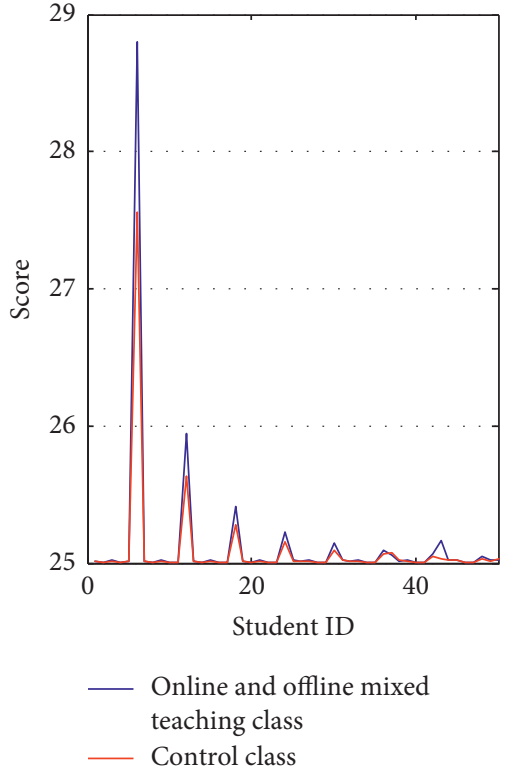

(b)

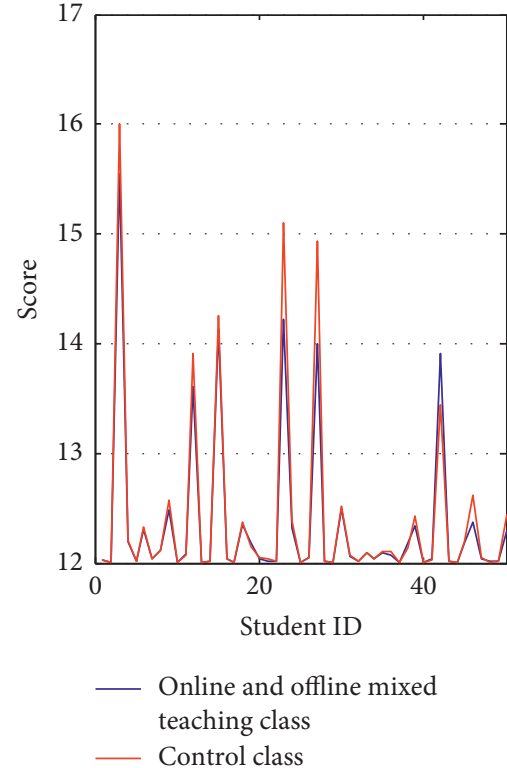

(c)

Figure 5: Pretest statistics of three dimensions of college English learning in online and offline mixed teaching classes and control classes. (a) Text understanding anxiety. (b) Emotional anxiety. (c) Cultural background anxiety.

average value of the control class is about 25.8 points, and the average value of the online and offline mixed teaching class is about 25.6 points. It can be seen that the two classes are in terms of text comprehension anxiety. From the perspective of emotional anxiety, the average value of the control class is about 25.4 points, and the average value of the online and offline mixed teaching class is about 25.1 points, indicating that the average gap in emotional anxiety is also small. From the perspective of cultural background anxiety, the average value of the control class is about 13.1 points, and the average value of the online and offline mixed teaching class is about 13.3 points. It can be seen that the two classes have a small difference in the scores of cultural background anxiety. Before the experiment, the students in 
both classes had the same degree of reading anxiety during their English reading learning process, and the two classes met the experimental conditions.

5.2. Analysis of Posttest Results of Students Learning College English. It can be seen from Figure 6 that, after the teaching experiment, the average posttest reading anxiety of the online and offline mixed teaching class is about 51.7 points, and the average of the control class is about 65.2 points. The average posttest learning anxiety of the online and offline mixed teaching classes was lower than the average of the control classes. These data show that, after teaching experiments, students in the online and offline mixed teaching classes have a certain degree of relief in English reading anxiety, while the students in the control class may have higher learning anxiety due to the final exam and other reasons.

In this paper, the posttest results of the questionnaires of the two classes are also descriptive statistics from three dimensions (text comprehension anxiety, emotional anxiety, and cultural background anxiety), as shown in Figure 7.

It can be seen from Figure 7 that, after the experiment, from the perspective of text comprehension anxiety, the average value of the control class is about 27.5 points, and the average value of the online and offline mixed teaching class is about 25.4 points. There are differences in anxiety; from the perspective of emotional anxiety, the average value of the control class is about 28.6 points, and the average value of the online and offline mixed teaching class is about 25.9 points, indicating that there is a large gap in the average value of emotional anxiety; from the perspective of cultural background anxiety, the average value of the control class is about 13.8 points, and the average value of the online and offline mixed teaching class is about 12.9 points. It can be seen that the scores of the two classes in the cultural background anxiety dimension are slightly different. In summary, the two classes have some gaps in their college English scores after the experiment.

The learning of cultural background knowledge requires students to accumulate for a long time, so, in a semester, students will still feel a lack of background knowledge of articles. Therefore, through the analysis and discussion of the above data, we can conclude that the English reading anxiety level of the two classes of students has significant differences in the two dimensions of text comprehension anxiety and emotional anxiety. Although there is no significant difference in cultural background anxiety, there is no significant difference. We can see that there is still a slight gap in the scores of the two classes in this dimension after the experiment.

Because this article compares and analyzes the English reading anxiety levels of the two classes before the experiment, it is concluded that they have the same teaching content, teaching teachers, and class schedules. From this, we can verify the first research question; that is, the Internetbased scaffolding teaching model can increase reading confidence, reduce students' English reading anxiety, and gain a sense of learning achievement.
5.3. Analysis of Pre-and Posttest Results of Students' Academic Performance in Online and Offline Mixed Teaching Classes and Control Classes. This article conducts a horizontal analysis of the data in the first two parts. In order to analyze the data more accurately, this article will make descriptive statistics on the English learning performance values of the two classes of students to make the experimental data more convincing.

Before the experiment, the academic performance of the online and offline mixed teaching class was similar to that of the control class. It can be seen from Figure 8 that, after the experiment, the average score of the online and offline mixed teaching class has increased by about 8.3 points. It can be seen that, after the experiment, the English learning performance value of the students in the online and offline mixed teaching class has greatly improved. According to Satio's standard of academic performance, $20-46$ is divided into low performance level, 47-68 is divided into medium performance level, and $69-100$ is divided into high performance level, which shows the learning of students in online and offline mixed teaching classes. A high level of achievement has been reached. This shows that the new teaching model has a significant effect on improving students' English learning performance. However, compared with online and offline mixed teaching classes, the average academic performance of the control class before and after the experiment is lower. This shows that, after a semester of teaching, the English learning performance of the students in the control class has not improved and is still at a low level.

In order to further verify the practical effect of the new teaching model, this article will conduct specific analysis and discussion from three dimensions: text comprehension score, learning emotion score, and cultural background score.

5.3.1. Text Comprehension Score. The data in Figure 9 show the postdescriptive statistical results of text comprehension scores in online and offline mixed teaching classes and control classes. From the data in the figure, it can be seen that the average text comprehension score of the online and offline mixed teaching class after the experiment is about 84.5 points, while the average value of the control class is about 77.5 points. It can be seen that, from the perspective of the text comprehension score, after the experiment, the text comprehension score of the online and offline hybrid teaching class is better than that of the control class.

5.3.2. Learning Emotion Score. Figure 10 shows the descriptive statistical results. It can be seen that, from the perspective of emotional performance, after the experiment, the emotional score of the online and offline mixed teaching class has increased rapidly.

5.3.3. Cultural Background Score. Figure 11 shows the descriptive statistical results of the posttest of cultural background scores in online and offline mixed teaching classes 


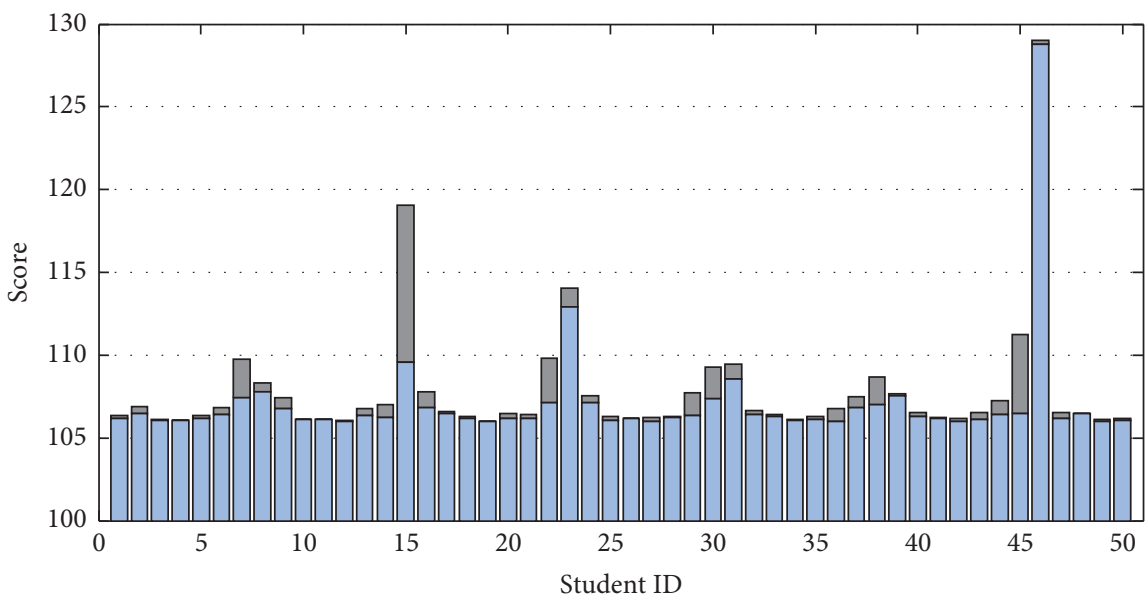

Online and offline mixed teaching class Control class

FIGURE 6: Comparison results of posttest description of learning anxiety of students in control classes and online and offline mixed teaching classes.

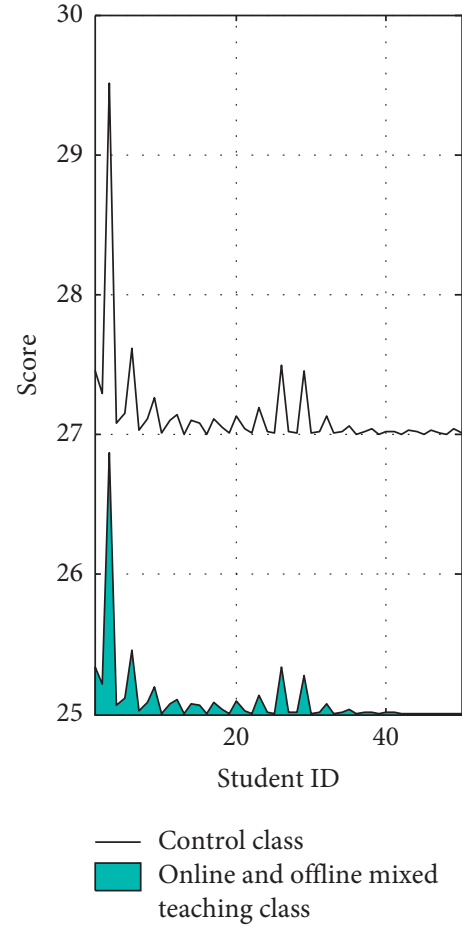

(a)

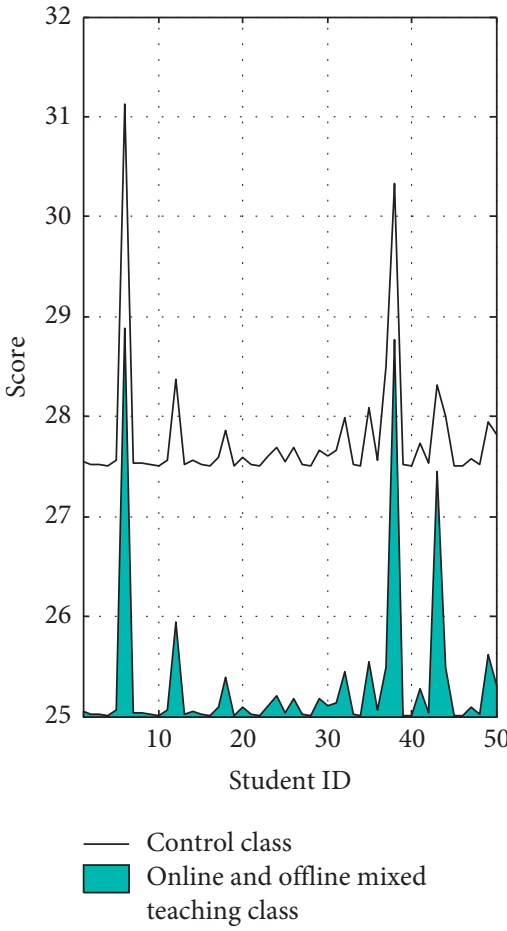

(b)

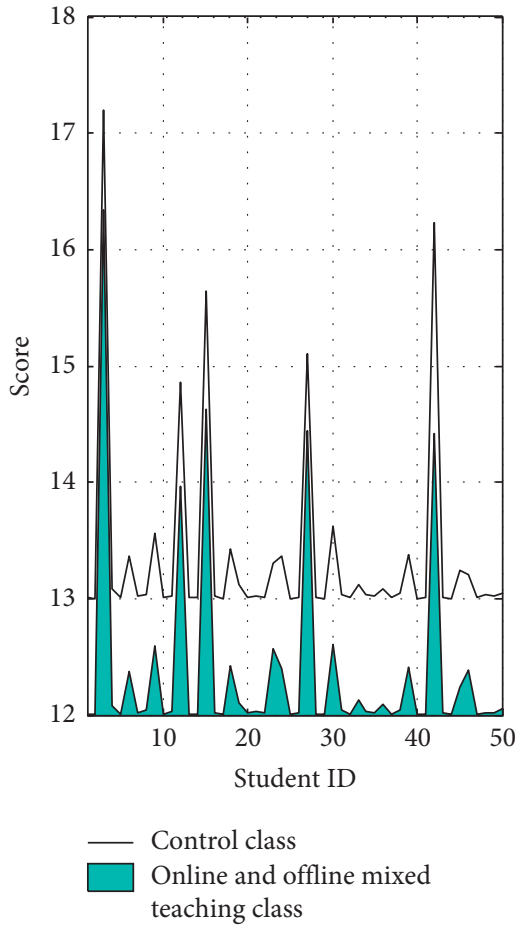

(c)

Figure 7: Descriptive statistics of the three dimensions of college English learning in online and offline mixed teaching classes and control classes. (a) Text comprehension anxiety posttest. (b) Emotional anxiety posttest. (c) Cultural background anxiety posttest. 


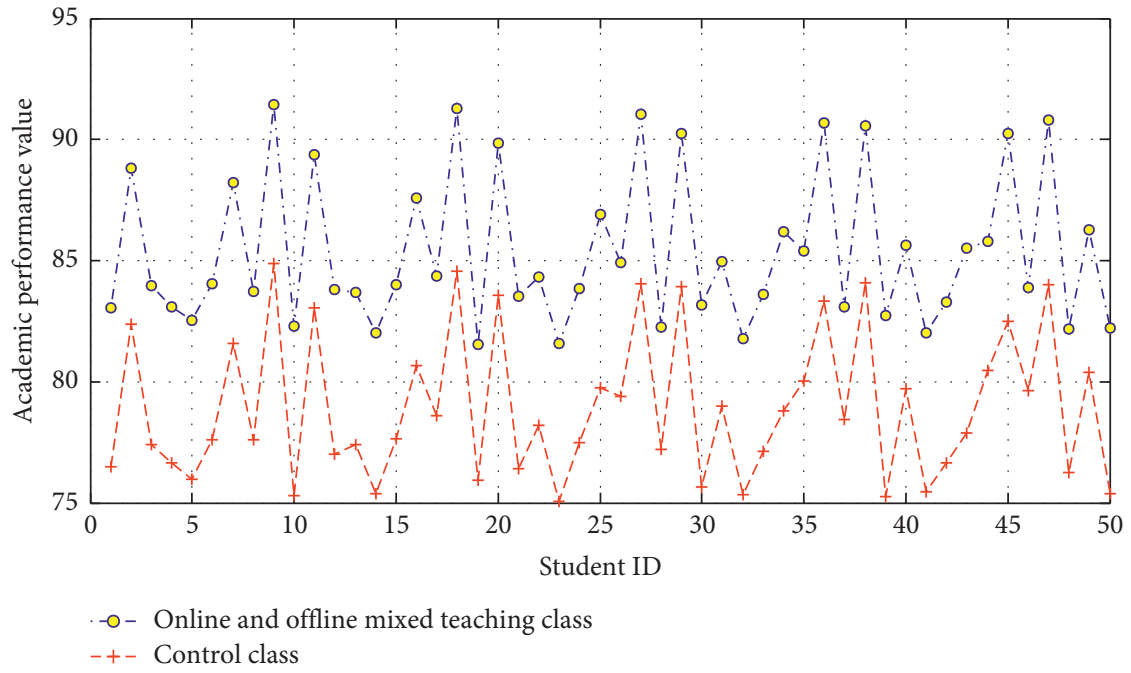

Figure 8: Posttest descriptive statistics of learning performance in online and offline mixed teaching classes and control classes.

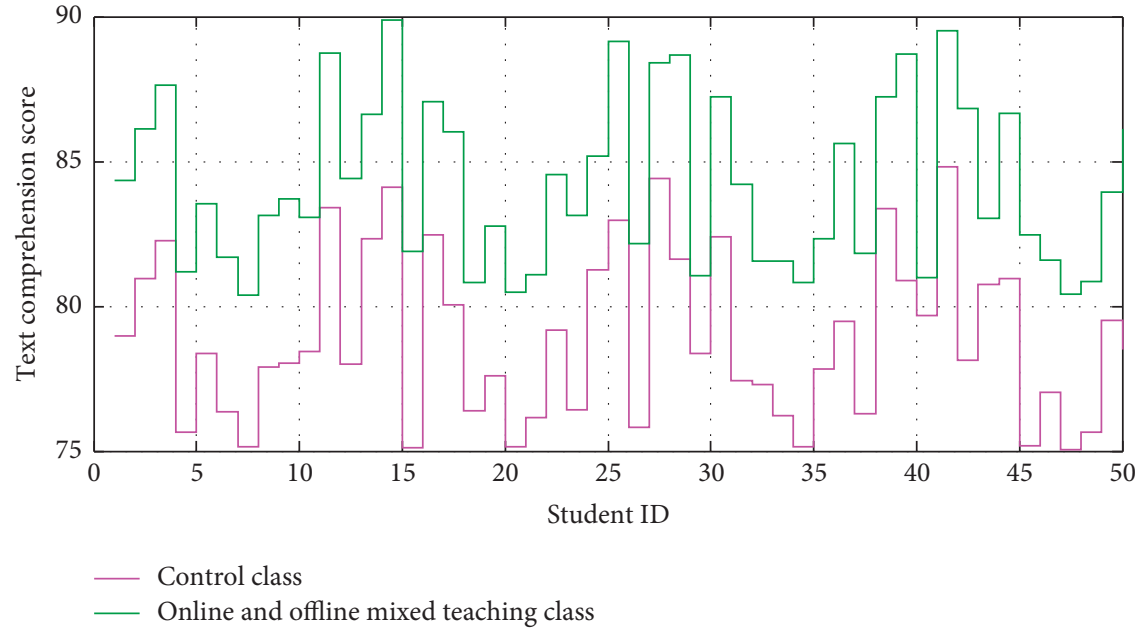

Figure 9: Posttest descriptive statistics of text comprehension scores in online and offline mixed teaching classes and control classes.

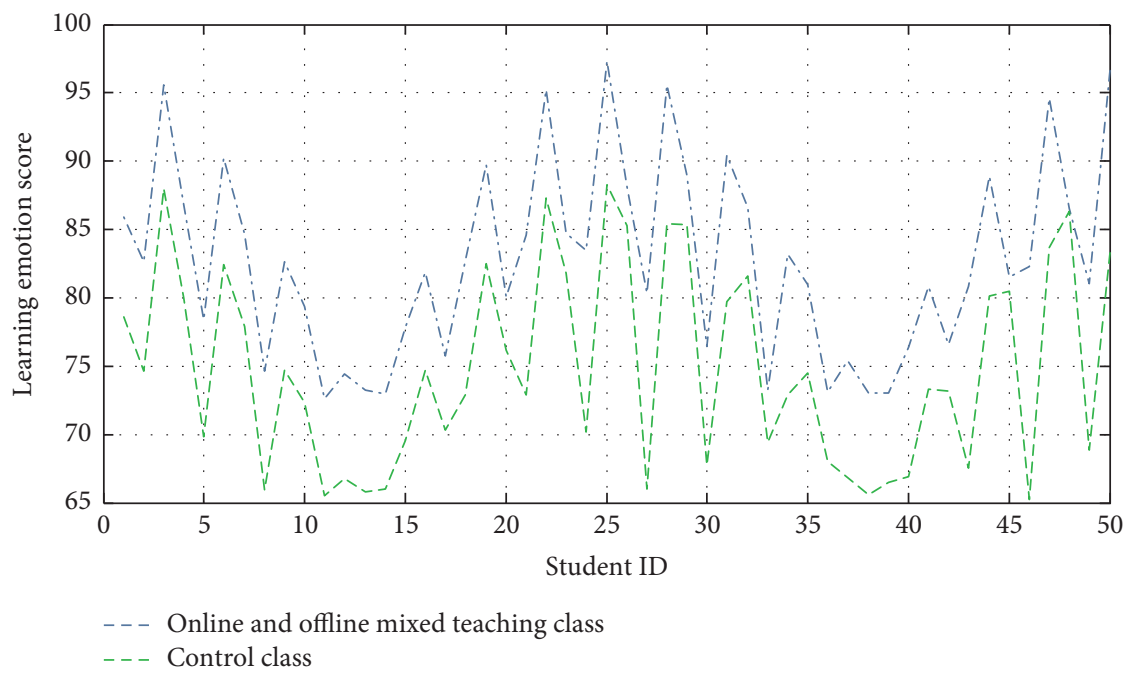

FIgURE 10: Posttest descriptive statistics of learning emotion scores in online and offline mixed teaching classes and control classes. 


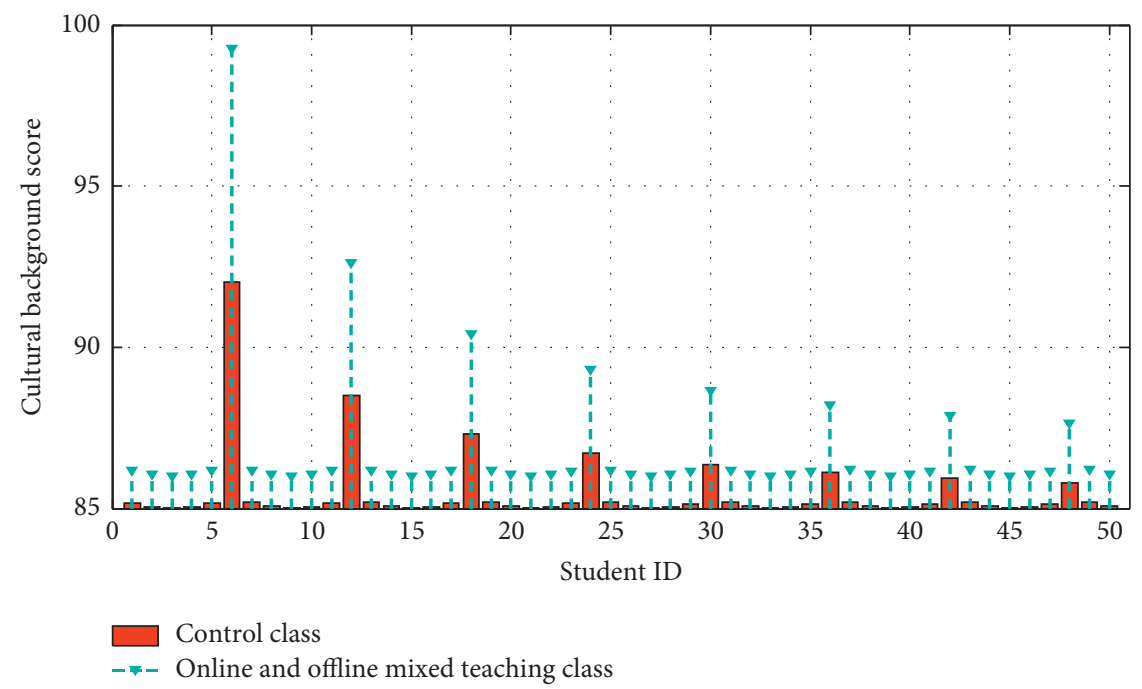

Figure 11: Posttest descriptive statistics of cultural background scores in online and offline mixed teaching classes and control classes.

and control classes. It can be seen that, after the experiment, the average value of the cultural background score of the online and offline mixed teaching class is about 87.9 points, and the average value of the control class is about 86.1 points.

\section{Conclusion}

This article expounds the current domestic and foreign development of computer Internet technology and introduces the application of computer Internet technology in education and teaching. This paper explains the principle of computer Internet technology and its transmission protocol and emphatically introduces the streaming transmission and on-demand playback methods suitable for the platform system. Media selection theory, learning theory, and individualized learning theory all provide a good theoretical foundation for the application of computer Internet technology to college teaching. The system requirements analysis and design process of the platform are described, and the function realization of each module is described. The Internet-based scaffolding teaching model can improve students' English reading performance. Comparing the scores before and after reading the test papers, it is found that the scores of the students in both classes have improved, but the reading scores of the online and offline mixed teaching classes have improved even higher; and, through interviews with students, this article found that students in online and offline hybrid teaching classes can actively participate in learning activities and complete learning tasks assigned by the teacher. The only difference is the teaching method. This shows that the Internet-based scaffolding teaching model helps students develop a sense of achievement and selfconfidence in reading and develop a sense of autonomous learning. Students' attitudes towards the Internet-based scaffolding teaching model are positive. Through interviews with students, this article learned that students believe that the Internet-based scaffolding teaching model can give them sufficient time for autonomous learning before class.

\section{Data Availability}

The data used to support the findings of this study are included within the article.

\section{Conflicts of Interest}

The authors declare that they have no conflicts of interest.

\section{References}

[1] Y. Yao, "Blended teaching reform of higher vocational education based on addie teaching design model," Journal of Frontiers of Society, Science and Technology, vol. 1, no. 5, pp. 60-65, 2021.

[2] Z. Liu, "Research on college english mixed teaching mode under information technology environment," Revista Argentina de Clinica Psicologica, vol. 29, no. 5, pp. 1673-1681, 2020.

[3] H. Sun, "A SPOC teaching mode of college english translation based on "rain classroom"," International Journal of Emerging Technologies in Learning (iJET), vol. 14, no. 17, pp. 182-193, 2019.

[4] Y. Li, "Construction of mixed classroom in higher vocational english teaching under MOOC," Online Learning, vol. 19, pp. 15-65, 2019.

[5] Y. Wang and X. Ma, "Research on blended teaching ability of college english teachers," Open Journal of Social Sciences, vol. 8, no. 12, pp. 308-319, 2021.

[6] Y. Shisheng, "Study on the mixed teaching model of college teaching under the background of educational informationization," Studies in Literature and Language, vol. 20, no. 3, pp. 28-32, 2020.

[7] Z. Zhou, "On the lesson design of online college english class during the COVID-19 pandemic," Theory and Practice in Language Studies, vol. 10, no. 11, pp. 1484-1488, 2020.

[8] L. Yang, "The teaching design of computer network's flipped classroom based on fanya SPOC teaching platform," Sino-US English Teaching, vol. 15, no. 2, pp. 87-91, 2018.

[9] Y. Gao, "Blended teaching strategies for art design major courses in colleges," International Journal of Emerging 
Technologies in Learning (iJET), vol. 15, no. 24, pp. 145-158, 2020.

[10] Z. Xu and Y. Shi, "Application of constructivist theory in flipped classroom-take college english teaching as a case study," Theory and Practice in Language Studies, vol. 8, no. 7, pp. 880-887, 2018.

[11] Y. Jia and L. Zhang, "Research and application of online SPOC teaching mode in analog circuit course," International Journal of Educational Technology in Higher Education, vol. 18, no. 1, pp. 1-14, 2021.

[12] S. Hua and F. Liu, "A new hybrid teaching model for a psychology course," International Journal of Emerging Technologies in Learning (iJET), vol. 16, no. 3, pp. 206-219, 2021.

[13] C. Wang, "Employing blended learning to enhance learners' english conversation: a preliminary study of teaching with hitutor," Education and Information Technologies, vol. 26, no. 2, pp. 2407-2425, 2021.

[14] I. Mutambik, "The Role of e-learning in studying english as a foreign language in Saudi Arabia: students' and teachers' perspectives," English Language Teaching, vol. 11, no. 5, pp. 74-83, 2018.

[15] M. Huang, Y. Shi, and X. Yang, "Emergency remote teaching of english as a foreign language during COVID-19: perspectives from a university in China," IJERI: International Journal of Educational Research and Innovation, vol. 1, no. 15, pp. 400-418, 2021.

[16] X. U. Li, "English and American literature teaching in colleges and universities in the new media age," Higher Education of Social Science, vol. 18, no. 1, pp. 41-44, 2020.

[17] S. R. Milonm and H. Hasanand Ipban, "Students' perception towards technology in learning english as a foreign language: a case study of higher secondary students of Pabna, Bangladesh," IOSR Journal of Humanities and Social Science, vol. 22, no. 6, pp. 47-53, 2017.

[18] M. Li, Z. An, and M. Ren, "Study on student-centered artificial intelligence online teaching+ home learning model during the COVID-19 epidemic," Inteligencia Artificial, vol. 23, no. 66, pp. 51-65, 2020.

[19] N. Aulia and R. W. Batubara, "Teachers' perception towards online english learning using distance education system at rural schools area, Thailand," International Journal of Multicultural and Multireligious Understanding, vol. 8, no. 1, pp. 338-347, 2021.

[20] J. Irudayasamy, S. Y. Uba, and C. A. Hankins, "Exploration and exploitation of mobile apps for english language teaching: a critical review," English Language Teaching, vol. 14, no. 4, pp. 43-54, 2021.

[21] T. Grubljesic, P. S. Coelho, and J. Jaklic, "The shift to socioorganizational drivers of business intelligence and analytics acceptance," Journal of Organizational and End User Computing, vol. 31, no. 2, pp. 37-64, 2019.

[22] L. Z. Zhang, M. Mouritsen, and J. R. Miller, "Role of perceived value in acceptance of "bring your own device policy"," Journal of Organizational and End User Computing, vol. 31, no. 2, pp. 65-82, 2019.

[23] A. Shahri, M. Hosseini, K. Phalp, J. Taylor, and R. Ali, "How to engineer gamification: the consensus, the best practice and the grey areas," Journal of Organizational and End User Computing, vol. 31, no. 1, pp. 39-60, 2019. 